\title{
A Habit of Social Action: Understanding the Factors Associated with Adolescents Who Have Made a Habit of Helping Others
}

\author{
Emma Taylor-Collins ${ }^{1}$ (D) Tom Harrison ${ }^{2} \cdot$ Stephen J. Thoma $^{3} \cdot$ Francisco Moller $^{4}$
}

Published online: 27 November 2018

(C) The Author(s) 2018

\begin{abstract}
Youth social action-activities such as volunteering, campaigning, and fundraising — has gained traction in the UK and internationally in recent years as governments have supported initiatives to encourage adolescents to develop a 'habit' of social action. However, there is not convincing evidence on what a habit of social action is. This study involved a questionnaire with 4518 16-20-yearolds in the UK and finds that moral and civic virtue identity, perceived behavioural control, goal direction, and subjective norms are related to a habit of youth social action. A key contribution of this study is the development and application of a new measure of virtue identity-the Virtue Identity Measure-to which we pay particular attention in this article.
\end{abstract}

Keywords Habit · Virtue identity · Adolescents · Youth social action · Volunteering

Emma Taylor-Collins

taylor-collinse@cardiff.ac.uk

1 Wales Centre for Public Policy, Cardiff University, 10-12 Museum Place, Cardiff CF103BG, UK

2 School of Education, University of Birmingham, Muirhead Tower, Birmingham B15 2TT, UK

3 Educational Psychology, University of Alabama, Carmichael Hall, Tuscaloosa 35487, USA

4 Jubilee Centre for Character and Virtues, University of Birmingham, Muirhead Tower, Birmingham B15 2TT, UK

\section{Introduction}

There has been significant global investment in volunteering, specifically youth volunteering, in recent years, from the United Nations' 2001 International Year of Volunteers promoting volunteering across over 200 cities worldwide (United Nations 5 December 2001) to the Sustainable Development Goals encouraging youth activism (United Nations 2015: 12, Article 51). In the west, the last 20 years have seen the introduction of mandatory community service for secondary school students in Ontario, Canada; increased youth volunteering in the USA (Metz 2014: 977); a National Volunteering Strategy from the Australian government (Australian Government 2011); and over 100,000 young people volunteering with the European Union's European Voluntary Service (European Voluntary Service 2016). In the UK, David Cameron's Big Society-framed as shifting power from the state to citizens-set out a role for young people through the practice of active citizenship (Evans 2011). In this context, the cross-sector, cross-party \#iwill campaign, involving over 800 organisations, was established to promote 'youth social action': 'young people taking practical action in the service of others to create positive change' (\#iwill 2017b). In this paper, we adopt this term 'youth social action'.

The \#iwill campaign aims to make social action a 'habit for life' (\#iwill 2017a). While there have been recent conceptual developments in this area (Lamb et al. 2019), to our knowledge there has been no empirical research treating a habit of social action as more complex than simply frequency of behaviour, or exploring factors associated with such a habit. This concern is the focus of the present article.

This paper explores the factors associated with habitual behaviour, drawn from an investigation of relevant 
philosophical and psychological literature. We aim to make a significant contribution to the literature on habits, proposing that it is possible to identify a habit of social action in adolescents, and advance practical understandings of a habit of social action to inform the work of youth social action providers. In particular, we develop a new Virtue Identity Measure, designed to test adolescents' identification with four virtue types-civic, intellectual, moral, and performance (Jubilee Centre for Character and Virtues 2017).

This paper draws on the quantitative findings from a larger, mixed-methods study of a habit of social action (Arthur et al. 2017), where we also examined the quality of the social action experience and whether it relates to a habit (this is also explored further in Lamb et al. 2019).

\section{Youth Social Action}

We use the term 'youth social action', because it is used in the UK-where this research was undertaken-by the \#iwill campaign and the government. Being a relatively new term, the literature on youth social action is limited, and so, this study is underpinned by the literature from volunteering, active citizenship, service, and other forms of prosocial behaviour. Youth social action incorporates a range of activities, including fundraising, volunteering, campaigning, and tutoring (Cabinet Office and Ipsos MORI 2016). Central to our understanding of social action is that it can benefit both the young person participating and the community or cause they are helping-it has a 'double benefit' (Birdwell et al. 2015; Arthur et al. 2015a).

\section{Theoretical Framework: Factors of Habit that Frame this Study}

Habits have been studied in relation to a wide range of behaviours, from exercise (Aarts et al. 1997), to the use of public transport (Verplanken et al. 1994), job-searching (van Ryn and Vinokur 1992), and blood donating (Lee et al. 1999). Some of the earliest theorisations of habit originate with Aristotle, who asserted that 'virtue of character (ēthos) is a result of habituation (ethos), for which reason it has acquired its name through a small variation on "ethos", (Aristotle 2000: 23). Empirical research on habits tends to be grounded in the Theory of Planned Behaviour (Ajzen 1991), which recognises that since behaviour often depends on opportunity and resources, if it is not perceived to be within a person's control then they are less likely to succeed. The Theory of Planned Behaviour has been widely used in research on habits, including in studies involving young people (Hewitt and Stephens 2007; Berg et al. 2000; de Leeuw et al. 2015), and informs our approach.

In our literature review, drawing primarily on philosophical and psychological theory, we identified five key components of habit. A habitual behaviour is found to be: performed frequently; part of virtue identity; within an individual's perceived behavioural control; in keeping with subjective norms; and goal-directed. Below we introduce each of these and explain their relevance for our study.

\section{Frequency of Participation}

When a behaviour has been performed frequently in the past, it is more likely to be performed frequently in the future (Astin et al. 1998; Ouellette and Wood 1998; Lally et al. 2010; Meer 2013; Marta et al. 2014). 'Habit' is therefore often used interchangeably with frequency of behaviour (Landis et al. 1978; Rosen and Sims 2011).

Conceptualising habit in terms of frequency is similar to the way habit is considered in common usage (Mittal 1988; Aarts et al. 1998). Though frequency of current and past behaviour is a good indicator of whether a behaviour has become a habit, we argue that it is but one component of habit formation.

\section{Virtue Identity}

Adolescence is a distinct phase of identity formation (Erikson 1968) - though the way in which it forms is not necessarily a universal experience (Markus and Kitayama 1991) — and civic engagement is said to be a key arena for this formation (Hall et al. 1999). Moral identity is 'the degree to which being a moral person is important to a person's identity', and subsequently how it is reflected in a person's actions (Hardy and Carlo 2011: 212); virtues are 'those character traits that enable human beings to respond appropriately to situations in any area of experience'; and virtue identity is 'understanding oneself as strongly committed to the virtues' (Jubilee Centre for Character and Virtues 2017: 3, 8). For virtuous actions to occur, the individual must prioritise the moral value above other values and setting considerations (for example, Blasi 2005; Rest 1983). As both Rest and Blasi suggest, individuals may understand the moral norms and be able to identify their features in practice; they may also be able to recognise the benefits of acting in accordance with their understanding of the moral ideal and yet not act in a virtuous way. In these models, virtuous action is claimed to vary from person to person as a result of motivational processes that elevate the moral. For Blasi, moral motivation is tied to the self and the development of an identity in which acting in concert with one's moral understanding is prioritised. Similarly, Rest (1983), in Component 3 of his 
Four Component Model, highlights the role of elevating moral values and suggests that cognitive and affective processes organised by the self-system contribute to moral motivation. Taken together, these motivational models focus on differences between individuals in terms of the priority placed on moral values within the self-systems that, in turn, promote moral actions.

As a guide towards measuring moral motivation, these models suggest that as moral values become more central to the self they should become more salient and accessible to the individual. Consistent with this view, adolescents who habitually act in prosocial ways ought to be more aware of the moral values expressed in their acts, should make the importance of these values known to othersparticularly friends and family - and be sensitive to similar orientations in others. However, existing measures of the priority placed on virtuous actions and attitudes only partially attend to these indicators (Berkowitz and Lutterman 1968; Pancer and Pratt 1999; Penner 2002; Metz and Youniss 2003). Perhaps the research tradition that aligns most closely with models of moral motivation is the work of Hart and Fegley (1995). They explored the idea of the 'altruistic personality' and self-concepts, testing the hypothesis that those involved in 'prosocial activities' are more likely to describe themselves in terms of moral personality traits, moral aspirations, and moral actions. However, missing from this work is an indication of how the individuals see their virtuous actions to be understood and recognised within their social network. We see this addition as an important omission given the importance of significant others in supporting the development of the self (for example, Moshman 2011).

To address these shortcomings in the available instruments used to assess virtue identity in adolescents, we created a new measure for the purposes of this study. The resulting Virtue Identity Measure (VIM) borrows from the previous studies (for example, Hart and Fegley 1995) by focusing on the ways in which the individual defines the self in terms of virtues. Importantly, the VIM extends this work by attending to the individual's perceptions of what would be ideal and characteristic expression of the virtues. In addition, the VIM assesses the individual's perception of how significant others (i.e., friends) might recognise the presence of the virtues in their character.

\section{Perceived Behavioural Control}

In order for a behaviour to become habitual, an individual must be able to perform the behaviour (Ajzen and Driver 1991). This means an individual having the resources they need (Callero et al. 1987) and believing that they are able to perform the behaviour (Ajzen and Driver 1991). It is difficult to test an individual's ability to participate in an activity such as social action through a questionnaire, so measures of perceived behavioural control can be used as a proxy (Aarts et al. 1997; Flanagan et al. 2007).

This also relates to 'helping efficacy', which has its basis in Bandura's (1977) self-efficacy. Amato (1990) found that planned helping was associated positively with helping efficacy, though no association was found between helping efficacy and spontaneous helping, reinforcing the importance of intention. In addition, van Ryn and Vinokur (1992: 593) tested self-efficacy and the theory of reasoned action and found that 'self-efficacy generates expectancies that one can perform the behaviour successfully, which in turn are likely to increase the intention to perform the behaviour'. We also identified four key enablers of youth social action:

- Time: The most common reason given for not participating in youth social action by 10-20-year-olds (Pye and Michelmore 2017).

- Confidence: Perceived lack of confidence is a barrier to participation in social action (Bown et al. 2014).

- Skills: Perceived lack of skills or experience needed to volunteer was found to be a bigger driver for 16-24year-olds than older age groups for not volunteering (Low et al. 2007: 69).

- Opportunity: In a survey with 15-19-year-olds, 'nearly half felt that it wasn't easy for young people to find out about volunteering opportunities' (Gaskin 1998: 36).

This evidence shows that a behaviour must be possible, and individuals must consider themselves capable of performing that behaviour, in order for it to be performed at all and therefore in order for it to become habitual.

\section{In Keeping with Subjective Norms}

Subjective norms are 'perceived social pressures' from important others to perform an action or not (Ajzen and Driver 1991: 188). Important others with significant influence on adolescents' civic engagement are parents and teachers (Andolina et al. 2003).

Subjective norms influence whether or not a behaviour is habitual through important others role-modelling the behaviour (Clary and Miller 1986; Andolina et al. 2003; Steutel and Spiecker 2004; Flanagan et al. 2007; Grönlund 2011; Law et al. 2013; Marta et al. 2014), expecting it (Callero et al. 1987; Hart and Fegley 1995), encouraging and valuing it (Hart and Fegley 1995; Pancer and Pratt 1999), and providing support for it to occur (Marta and Pozzi 2008).

This suggests that considering the influence of others over a young person's behaviour is an important component of behaviour and likely of habit. We therefore explored the approval and expectations of parents and 
friends in our study as well as perceptions of parents' and friends' behaviour.

\section{Goal Direction}

In the Theory of Planned Behaviour, intention is considered to be highly important in predicting future behaviour (Ajzen 1991). This is reflected in evaluations of youth social action programmes, in which adolescents are often asked about their intentions to continue taking part in social action (Breeze and Thornton 2006; National Youth Agency 2013; Booth et al. 2014; Ipsos MORI 2014; Kirkman et al. 2015). Although intentions are important to habituation, we argue that they are insufficient as a stand-alone measure of habit. For example, Marta et al. (2014) find perceived behavioural control and frequency of past volunteering to be more important than intentions in predicting future volunteering, and intentions do not always translate into action (Omoto and Snyder 1995). Linked to this, studies also highlight the importance of a goal (Aarts et al. 1998; Ouellette and Wood 1998; Gollwitzer 1999), and as Verplanken and Orbell (2003: 1314-1315) explain, getting the 8.10 am bus to work can be habitual, but the goal-getting to work on time-must be activated in order for this habitual behaviour to be expressed.

\section{Hypothesis}

We have identified five important components of a habit in a range of contexts. The definition of habit we use in this study is based on the basic definition of habit identified in the literature and relates to previous and intended behaviour: an adolescent who has participated in social action in the past 12 months and states they definitely will or very likely will participate again in future is said to have made a habit of social action.

Our research question is: are frequency of participation in social action, virtue identity, perceived behavioural control, subjective norms, and goal direction associated with a habit of social action among 16-20-year-olds in the UK?

\section{Method}

We used a cross-sectional survey design, often used in studies of habit (Verplanken and Orbell 2003; Kremers and Brug 2008; Lally et al. 2010) and of youth social action (Cabinet Office and Ipsos MORI 2016), to address the research question. An online questionnaire was chosen as the most suitable method because it enabled us to gather the views of a large number of respondents.

\section{Instruments}

Most of the questions used in our study were adapted or taken from previous studies. ${ }^{1}$ In addition to the measures detailed below, we also collected data on age, gender, ethnicity, and eligibility for Free School Meals (FSM) in the past 6 years (a proxy for low income). Below we report alphas where appropriate: where we measured a unidimensional construct and had sufficient scale points to make the statistic interpretable.

\section{Participation and Frequency of Participation in Social Action}

Participation in social action was assessed using a similar version of the question used in the National Youth Social Action Survey (Ipsos MORI 2015), adapted for online use: 'Have you done anything in the past 12 months to help other people or the environment (social action), other than donating money or goods?', followed by a list and explanation of six different activities. These were: fundraising or a sponsored event; helping improve your local area; campaigning for something you believe in; tutoring, coaching or mentoring anyone; supporting other people who aren't friends or relatives; and giving time to help a charity or cause. Respondents were asked to select activities in which they had been involved, if any.

Frequency of participation was measured by asking those who had participated in social action over the past 12 months how often they had done so for each activity in which they said they had been involved: once a week or more, once a fortnight or more, once a month or more, every few months or more, once/as a one-off, in the holidays, or don't know.

\section{Virtue Identity}

The Virtue Identity Measure (VIM) was designed to assess adolescents' recognition of the virtues as a component of the self. Unlike more traditional measures that focus solely on assessing the individual's endorsement of the virtues, the VIM provides vignettes describing realistic social exchanges and asks whether and to what degree the participants see themselves as acting like the character in the story. In addition, the measure allows the participant to judge whether other individuals, including friends, would appreciate the virtuous action and view it as a characteristic of the self. The resulting measure provides multiple indicators of how the individual views the virtue as a characteristic of the self and, as such, more closely captures the

\footnotetext{
${ }^{1}$ Additional questions related to the other research question in this study were also asked; these are not reported on in this paper.
} 
notion of moral identity as described in models of moral motivation (for example, Blasi 2005).

The VIM was constructed and piloted prior to its use in the current study. In constructing the measure, we began with the goal of creating realistic stories in which the characters had both positive and negative attributes. However, in piloting we found that writing vignettes in which positive and negative attributes were equally positive or equally negative led to stories that were obscure and judged to be less realistic. As such, we decided instead to remove the negative attributes and create four equally positive characters. We addressed any potential gender bias by ensuring the gender of the main character in each vignette corresponded to each participant's gender.

The vignettes developed in test construction phase were pilot-tested and refined in two stages with students aged 15-18 at two schools (one state, one grammar). Using student perceptions of the vignettes as realistic and plausible, the number of stories was reduced to four vignettes, each focusing on a character who represented one of the following virtue types: civic, intellectual, moral, and performance (Jubilee Centre for Character and Virtues 2014). To capture participants' responses to the four vignettes, participants were asked to respond to questions asking whether the protagonist in the story was someone that other people (both generally speaking and specifically one's friends) might think was like them, and whether the protagonist's actions were appreciated by significant others (see Appendix 1 for the full measure).

\section{Perceived Behavioural Control}

Perceived behavioural control was measured using questions adapted from Ajzen and Driver (1991), testing whether respondents feel they have the skills, time, opportunity and confidence to participate in social action $(\alpha=.61)$. Sample items are: 'I don't have the skills that I need to do social action' and 'I have the confidence that I need to do social action', using a five-point Likert scale ranging from strongly agree to strongly disagree.

\section{In Keeping with Subjective Norms}

The extent to which participation in social action is in keeping with subjective norms was tested using questions adapted from Marta et al. (2014). Separate questions were asked about whether participants had the support and encouragement they needed from friends and from family to participate in social action, using a five-point Likert scale (strongly agree-strongly disagree). These were followed by a question to assess the influence of friends/parents/guardians as role models for social action, measuring respondents' awareness of social action involvement by friends and parents/guardians $(\alpha=.74)$ : 'In the past 12 months, have either of your parents or guardians or any of your friends been involved in any of the following?', the options being the same activities asked about in the participation question.

\section{Goal Direction}

To measure goal direction, adolescents' motivations for participating in social action were tested using a 12-item adapted version $(\alpha=.87)$ of the 30-item Volunteer Functions Inventory (Clary et al. 1998), which measures six areas of motivation: protective, values, career, social, understanding, and enhancement. We tested responses to the two statements for each area with the highest factor loadings through items such as 'I feel it is important to help others' (values) and 'Social action is a good escape from my own troubles' (protective) using a five-point Likert scale (strongly agree-strongly disagree).

\section{Participants}

Participants in this study were 4518 16-20-year-olds living in the UK. Of the total respondents, $67 \%$ were female and $33 \%$ male. Forty per cent were aged $16,42 \%$ aged $17,12 \%$ aged $18,4 \%$ aged 19 , and $2 \%$ aged 20 . The majority were at sixth form or college $(85 \%)$. Seventy per cent identified as White and $30 \%$ as Black, Asian and Minority Ethnic (BAME). Twenty-four per cent had been eligible for Free School Meals in the past 6 years. Forty-two per cent practised a religion. $^{2}$

While a representative sample of adolescents involved in social action would have been ideal, this would have involved adding additional stages to this project which would have been prohibitively costly, complicated, and time-consuming. With a random sample likely to have resulted in fewer relevant respondents, we instead chose a purposive sample, aiming to reach adolescents who had already taken part in social action (but not necessarily made it a habit). In recruiting respondents, we worked with a diverse range of 12 organisations, schools and colleges from across the UK. Over half of respondents had participated in the National Citizen Service. The organisations provided access to adolescents who had already participated in their programmes, and the schools and colleges had been recognised for their social action provision by being featured on www.education.iwill.org.uk.

After four phases of piloting, we analysed the findings to check adolescents' cognitive understanding of the questions, completion time, internal validity, and functionality. The final questionnaire was live from July to September

\footnotetext{
${ }^{2}$ See Appendix 2 for full demographic data.
} 
2016. Following advice from the youth social action providers involved in this study, an incentive for taking the questionnaire was offered in the form of entry into a prize draw to win one of three personal development funds, and winners were selected using Excel's randomise function.

\section{Data Analysis Procedure}

Responses were exported from Survey Gizmo and merged in an Excel spreadsheet. Subsequently, the data were exported to SPSS version 22 for analysis. Owing to the questionnaire characteristics and the research questions, most of the analysis was descriptive. Three different groups were constructed based on past and probable future participation in social action (see Fig. 1): Habit, Non-habit, and Non-participant. Once the data were cleaned and filtered, cross-tabulation was used to identify differences between groups. Nonparametric tests were used to compare the distributions across them (Mann-Whitney for two samples and Kruskal-Wallis for three samples). The differences between the groups presented in this article are all statistically significant $(p=<.05)$, unless stated otherwise. Once the data were described, we tested the association between having a habit of social action and the analysed variables. We ran a binary logistic regression using the Habit/Non-habit variable as the binary dependent variable and the remaining variables as predictors: the value 1 was given to the category of interest (Habit) and the value 0 to those not belonging to that category (Non-habit). Logistic regressions are robust with auto-correlated data and multinormal distribution giving an adequate measure of the studied variables (Johnson 1998).

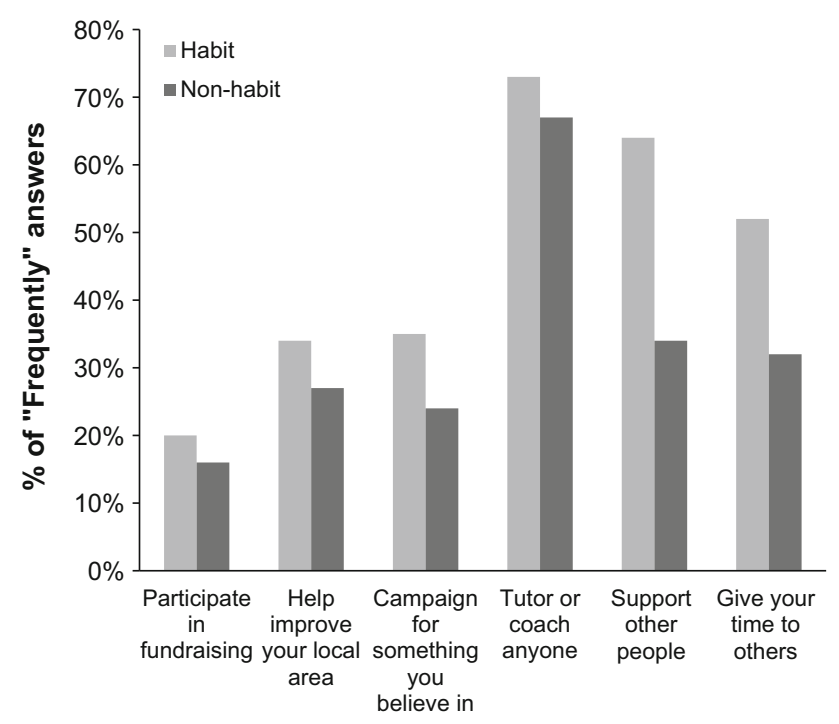

Fig. 1 How often do you participate in the following activities?

\section{Results}

While we originally intended to reach adolescents who had already been involved in social action, through the schools and colleges adolescents who had not previously been involved in social action were also recruited. This made it possible to divide respondents into three groups (Table 1: Three groups). Since intention to participate in future is central to the definition of habit used in this study, only respondents who said they were very likely to or would definitely participate in future were included in the Habit group.

Non-participants were not asked all of the questions, as some were contingent on prior involvement in social action; thus, for some findings reported, only the Habit and Non-habit groups are compared.

Around $14 \%$ of the Non-participant group are from a BAME background, similar to the national average. However, BAME adolescents are more likely to be in the Non-habit (27\%) and Habit (30\%) groups than the Nonparticipant group. When data are weighted to account for the higher number of female respondents, males and females are just as likely to be in the Non-habit group (51\% male versus $49 \%$ female), but females are underrepresented in the Non-participant group (64\% male versus $36 \%$ female) and overrepresented in the Habit group (39\% male versus $61 \%$ female). In addition, those practising their religion are more likely to be part of the Habit group (47\%) than the Non-habit (42\%) and Non-participant groups $(33 \%)$.

No statistically significant differences between groups in terms of socioeconomic status are found: $33 \%$ of Nonparticipants have been eligible for FSM in the previous six years, versus $26 \%$ in the Non-habit and the Habit groups.

\section{Frequency of Participation}

We found a link between a habit of social action and frequent participation in social action. Those in the Habit group are more likely to participate more frequently in social action than those in the Non-habit group across all the social action activities measured (Fig. 1). The greatest difference exists for those involved in supporting others (not including friends or relatives): $64 \%$ of the Habit group do this frequently, versus $34 \%$ of the Non-habit group.

\section{Virtue Identity}

The Virtue Identity Measure (VIM) tested respondents' level of identification and association with four virtue types-moral, civic, performance, and intellectual-using vignettes: each vignette described a person exemplifying 
Table 1 Three groups: Habit, Non-habit, and Non-participant

\begin{tabular}{|c|c|c|c|c|c|c|}
\hline Group & $N$ & $\begin{array}{l}\text { Age } \\
\text { (mean) }\end{array}$ & SD & $\begin{array}{l}\% \\
\text { BAME }\end{array}$ & $\begin{array}{l}\text { Eligible for free } \\
\text { school meals }(\%)\end{array}$ & $\begin{array}{l}\% \\
\text { female }\end{array}$ \\
\hline $\begin{array}{l}\text { Habit: Has participated in social action in the past } 12 \text { months and is very likely } \\
\text { or definitely will participate in the next } 12 \text { months }\end{array}$ & 1515 & 16.94 & .945 & 14 & 33 & 75 \\
\hline $\begin{array}{l}\text { Non-habit: Has participated in social action in past } 12 \text { months and is fairly } \\
\text { likely to, not that likely to, not at all likely to, definitely won't, or doesn't } \\
\text { know if they will participate in next } 12 \text { months }\end{array}$ & 1853 & 16.69 & .813 & 27 & 26 & 65 \\
\hline Non-participant: Has not participated in social action in past 12 months & 1150 & 16.98 & .943 & 30 & 26 & 53 \\
\hline Total & 4518 & & & & & \\
\hline
\end{tabular}

each virtue type. We found that a habit of social action is associated with greater familiarity with the virtues, closer identification with the virtues, and increased likelihood of having friends who are thought to appreciate exemplars of those virtues. Responses to each vignette were summarised in three ways. First, responses were summed within four identity indicators - the degree to which the virtues were judged to be: characteristic of the self; aspirational for the self; thought to be viewed by others as characteristic of the self; and appreciated by friends. The resulting four scores ranged from 0 (not at all) to 4 (a great deal). Second, and as a proxy for each respondent's familiarity with and the accessibility of the virtue concepts, we summed the use of the 'not sure' response option for the virtue types within these same categories (i.e., the self, the aspirational self, and perceived endorsement from friends and from others). These four scores also ranged from 0 (not familiar) to 4 (consistently familiar). Finally, we summed each respondent's rejection of the virtue types, as evidenced by their endorsement of the 'not at all like me' response option across the different identity categories. Again, the scores ranged from 0 (rejection of all virtues) to 4 (acceptance of the virtues). Taken together, these identity indicators provided an estimate of the degree to which respondents in each of the three groups see the virtues more or less clearly, see them as more or less central to the self, and assume that others see them in a similar way. Once these scores were created, we plotted them against the three groups in order to assess trends and mean differences.

As shown in Fig. 2, the Habit group scores higher across all assessments of the virtues-they are much more likely to say they think like the protagonist, would like to be like them, assume they are viewed by others as similar, and think their friends would like them. Interestingly, the ideal (like to be) is higher than actual (do think that way), which is how one typically views the disparity between actual and ideal conception of the self-particularly when the concept under consideration is viewed as important to the self (Higgins 1987). In addition, the Non-habit group always falls in between the two others.
As explained, Fig. 3 shows that the Habit group differs in their use of the 'not sure' category. The difference between groups is less clear between the Habit and Nonhabit groups, but there are differences on three out of four questions (no difference on the 'people say' question). The 'not sure' rating can be used as a proxy for sensitivity to, or familiarity with, the application of these virtues. Furthermore, comparisons can be made across categories since they are on the same scale. Thus participants in the Habit group are clearer about their own assessments of 'thinking like' and appreciating the virtue as compared to the perceptions of others (friends and others).

The final comparison (Fig. 4) focuses on the rejection of the virtue (i.e., the 'not at all' category). Again, the Habit group avoids this category, suggesting that participation in social action increases the link between the virtue and the self.

Finally, we found that $50 \%$ of those in the Habit group think they are more like the moral virtue exemplar, versus $41 \%$ of those in the Non-habit group and $31 \%$ of those in the Non-participant group. Those in the Habit group (13\%) think they are more like the civic virtue exemplar than those in the Non-habit (5\%) and Non-participant groups (3\%). Furthermore, those in the Habit group (61\%) are more likely to want to be like the moral exemplar than those in the Non-habit (48\%) and Non-participant groups (33\%). Those in the Habit group (37\%) are also more likely to want to be like the civic virtue exemplar than those in the Non-habit (20\%) and Non-participant (11\%) groups.

Overall, these findings show not only that the VIM is a useful tool for assessing adolescents' virtue identity, but also that the respondents in the Habit group seemed to be more familiar with the four virtues, identified more closely with them, and had friends whom they think would appreciate the exemplars. Analysis of various clusters is consistent with the view described by models of moral motivation suggesting that individuals who habitually participate in social action are also characterised as demonstrating a familiarity with the virtues and are 
Fig. 2 High scores for virtue exemplars. Error bars: 95\% CI

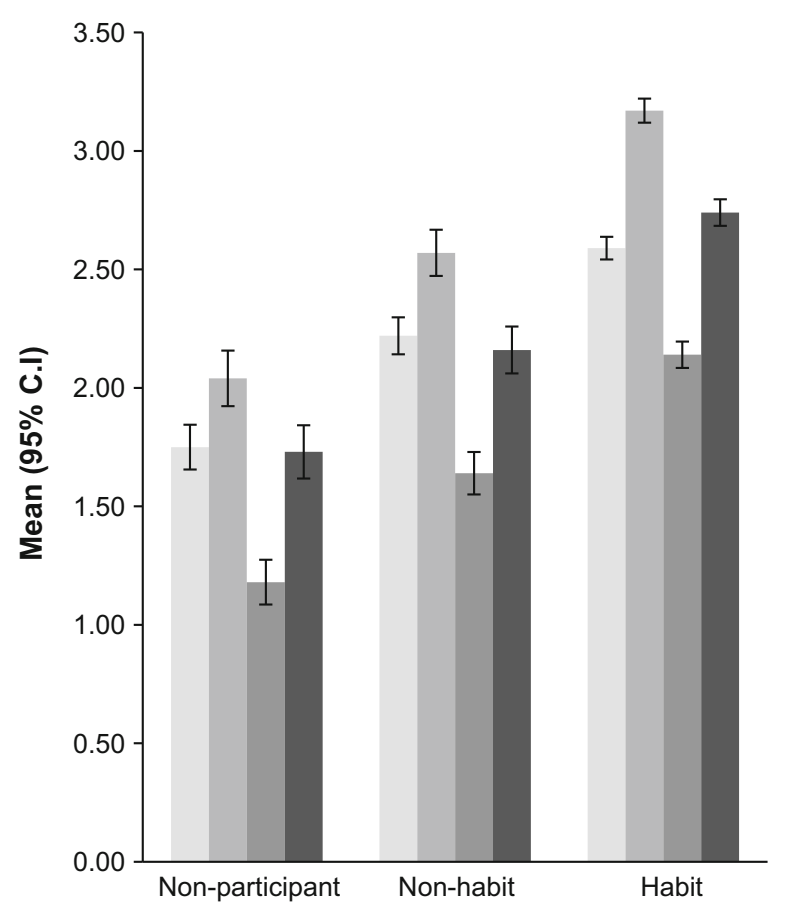

High score: Think am like

High score: Would like to be like

- High score: People would say am like

- High score: Friends would like
Fig. 3 'Not sure' scores for virtue exemplars. Error bars: $95 \%$ CI

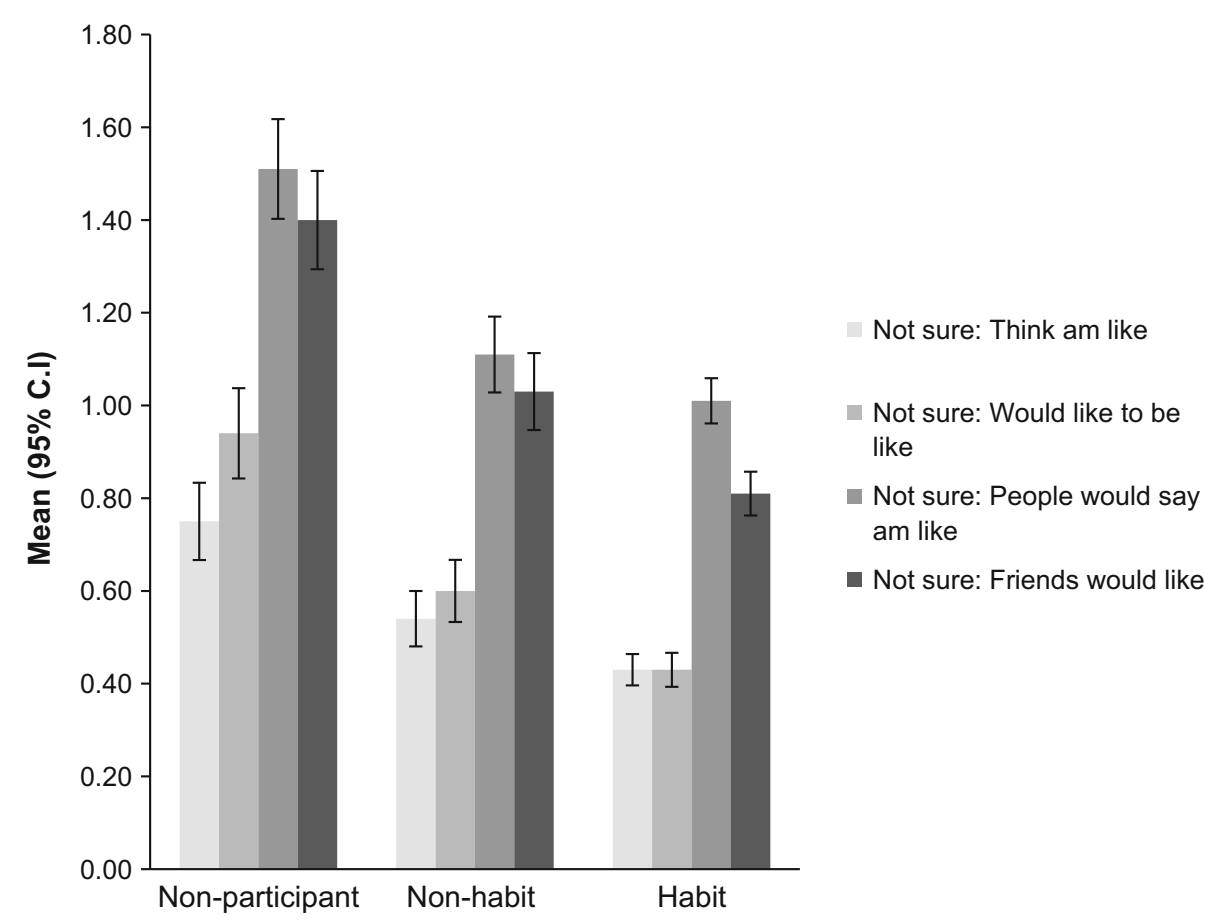

associated with people who encourage these acts (for example, Blasi 2005).

\section{Perceived Behavioural Control}

We found a link between perceived behavioural control and a habit of social action. Those in the Habit group are more likely than the Non-habit group to believe that they have the skills, time, opportunity, and confidence to participate in social action (Fig. 5). Seventy-six per cent of the Habit group agree that they have the necessary skills to participate, versus $61 \%$ of Non-habit respondents. In terms of time, $46 \%$ of the Habit group say they have enough time to be involved in social action, decreasing to $26 \%$ of the Non-habit group. Regarding opportunity, $73 \%$ of the Habit group believe the opportunity to be involved in social 
Fig. 4 'Not at all' scores for virtue exemplars. Error bars: $95 \% \mathrm{CI}$
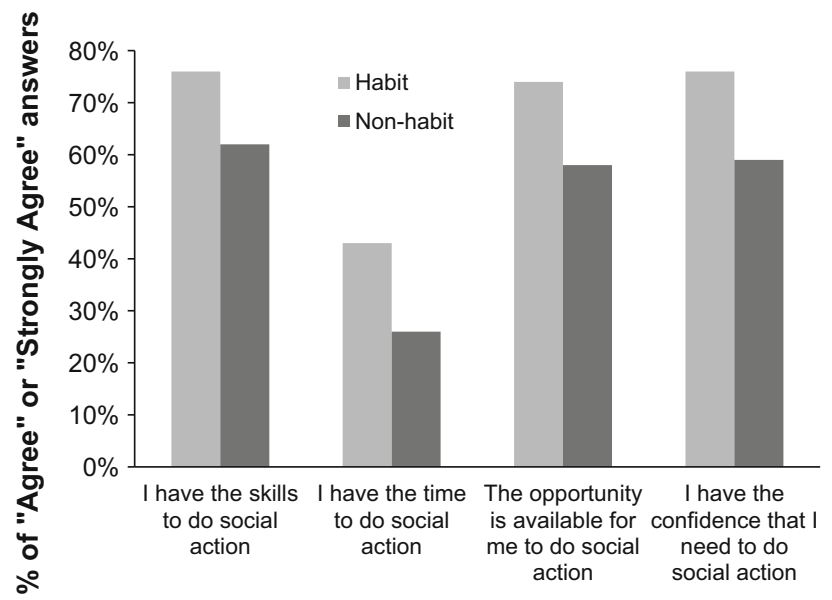

Fig. 5 Belief that it is possible to participate in social action

action is available to them, compared to $58 \%$ of the Nonhabit group. Finally, $76 \%$ of the Habit group say they have the confidence to participate in social action, versus only $59 \%$ of the Non-habit group.

\section{In Keeping with Subjective Norms}

Our findings show that social action is more likely to be in keeping with subjective norms for those with a habit of social action. Respondents in the Habit group say their parents/guardians participate in more social action activities than those of the Non-habit and Non-participant groups. As shown in Fig. 6, 11\% of parents/guardians of the Habit group are said to participate in five or more different types of social action, decreasing to 5\% among the Non-habit group and 2\% in the Non-participant group.

There is a positive association between parents'/guardians' participation in social action and their children's participation. The percentage of those in the Habit group who have supported other people rises from 35 to $49 \%$ when their parents are also said to be involved. Among the Non-habit group, this increases from 22 to $32 \%$. All activities show the same trend. On average, there is a $13 \%$ rise in adolescents' participation when their parents/guardians are said to be involved in the same type of social action.

Similarly, respondents in the Habit group tend to say they have friends who are involved in a wider range of types of social action compared to the Non-habit and Nonparticipant groups. As shown in Fig. 7, among the Habit group, $18 \%$ say their friends participate in four different types of social action; this figure decreases to $14 \%$ among the Non-habit group and $2 \%$ among Non-participants. This difference increases as we move along the $\mathrm{x}$-axis, increasing the number of activities.

Friends' participation increases the number of respondents involved in social action to a greater extent than parents'/guardians' participation. On average, there is a $14 \%$ rise in the Habit group's participation when they have a friend involved in the same type of social action (12\% in the Non-habit group).

If a young person says their parents/guardians or friends are involved in a particular type of social action, it is more likely that that young person is also involved in that type of 
Fig. 6 Parents'/guardians' involvement in social action

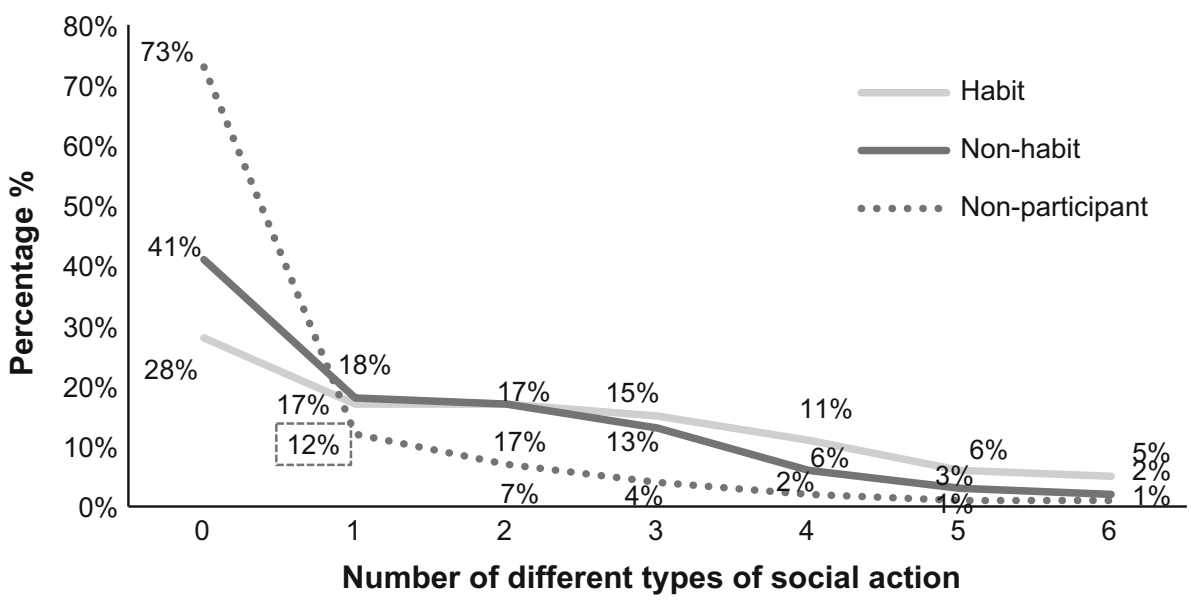

\section{Goal direction}

We found that a habit of social action is connected to stronger motivations to participate. Those in the Habit group are more likely to feel more strongly about all the motivations than those in the Non-habit group. The most important motivation for both groups relates to values: both are most likely to strongly agree with the statement 'I feel it is important to help others'. Roughly the entire sample agrees or strongly agrees with this statement in the Habit group (96\%); this figure slightly decreases (93\%) for the Non-habit respondents. The least popular motivation for both groups relates to subjective norms: 'Social action is important to my family and best friends'. Nonetheless, friends' and family's opinions appear to be more important for those in the Habit group compared to those in the Nonhabit group. Almost half (49\%) of the Habit group agree or strongly agree with the statement 'Social action is important to my family and best friends', versus 35\% of the Nonhabit respondents.

\section{Regression Analysis}

A binary logistic regression was conducted to predict the possibility of developing a habit of social action using all variables detailed in the findings above as predictors. As reported in Table 2, a Wald criterion analysis demonstrated that the following made a significant contribution to the prediction $(p=<.05)$ : gender; perceived behavioural control; the number of activities involved in; the age at which a young person first participated; and the perceived external association with a civic exemplar (agree that people say you are like). The influence of friends and parents, goal direction, and the other virtue identity items did not contribute to the model prediction.

Controlling for all the variables, it can be concluded that the most likely young person to develop a habit of social 
Table 2 Variables in the equation

\begin{tabular}{lccccc}
\hline & $\beta$ & SE & Wald & Sig. & Exp (B) \\
\hline Gender & .600 & .151 & 15.82 & .000 & 1.822 \\
Total Number of Activities & .313 & .052 & 36.85 & .000 & 1.367 \\
Age & & & 48.01 & .000 & \\
Age(1) & .769 & .166 & 21.42 & .000 & 2.157 \\
Age(2) & .993 & .197 & 25.47 & .000 & 2.699 \\
Age(3) & 1.275 & .207 & 37.87 & .000 & 3.579 \\
Civic exemplar & & & 35.04 & .000 & \\
Civic exemplar(1) & .630 & .234 & 7.27 & .007 & 1.878 \\
Civic exemplar(2) & .582 & .226 & 6.61 & .010 & 1.790 \\
Civic exemplar(3) & 1.095 & .242 & 20.39 & .000 & 2.990 \\
Civic exemplar(4) & 1.776 & .347 & 26.12 & .000 & 5.903 \\
Possibility & .225 & .028 & 63.80 & .000 & 1.253 \\
Constant & -5.655 & .497 & 129.34 & .000 & .004 \\
\hline Only significant resur
\end{tabular}

Only significant results are reported in this table action would: be female; have a strong belief that it is possible for them to participate in social action; and think that other people would say they are like a civic exemplar.

The Binary regression model test and summary can be found in Appendix 3.

\section{Discussion}

This study shows that it is possible to identify and measure a habit of youth social action, applying what is known already about habits from studies of behaviours in other fields (Aarts et al. 1997; Verplanken 2006; Mittal 1988). Through our study, we have shown that a habit of youth social action is about more than frequency of past behaviour and intended future behaviour. In designing this study, we identified that frequency of behaviour, virtue identity, subjective norms, perceived behavioural control, and goal direction have been shown to create a habit in behaviours such as seatbelt use, diet, and exercise. While our research cannot establish a causal relationship between these factors and a habit of social action, it is possible to state with some confidence, based on previous studies of habit, that it is likely that these five factors contribute to adolescents building a habit of social action. In addition, while anecdotally practitioners have assumed a link between these factors and a habit of social action, evidence now shows that this link does exist. Further experimental research is recommended in order to establish the direction of the relationship and identify causation. Furthermore, in the same way that different types of civic engagement are considered to have differential outcomes for participants (Ballard et al. 2018), we also recommend further exploration of how a habit of social action may vary depending on the activity.
For the purposes of this study, we developed a new tool to measure adolescents' virtue identity-the Virtue Identity Measure. A key finding from this measure is that virtue behaviour and self-identity are related, endorsing the findings from previous work by Hart and Fegley (1995). Furthermore, our study extends this work by showing that what a young person attributes to significant others about the individual's virtuous character also follows the pattern of being linked to action. This is a complex area and further research is required to understand the link between the findings on virtue identity and how they relate to the formation of habit by adolescents as they grow up. Utilising the VIM as part of a longitudinal study into moral and other types of virtue habits could be a fruitful new avenue of research.

Previous studies indicate that females are more likely than males to participate in social action (Pye and Michelmore, 2017), which is also reflected in our findings. While it could be argued that this is a result of gender differences in identity formation, it has been found that by late adolescence there are considered to be no significant differences in identity development according to gender (Klimstra et al. 2010).

We also found that demographic factors such as ethnicity and socioeconomic status do not appear to be barriers to adolescents developing a habit of social action. However, previous studies suggest that barriers do exist, with adolescents from a BAME background less likely to participate in 'meaningful' social action than their white peers (Pye and Michelmore 2017) and that those from lower socioeconomic backgrounds are less likely to participate in 'meaningful' social action than their more affluent peers (Pye and Michelmore 2017; Sarre and Tarling 2010; Mason et al. 2010). It is worth reiterating that our sample was not random, and therefore that our findings 
should be treated with some caution. Furthermore, social action is embedded into many of the schools and colleges involved in this study, and these are in less affluent areas where adolescents eligible for FSM may be overrepresented. Several youth social action providers involved also focus specifically on engaging adolescents from less affluent and from BAME backgrounds. Therefore, the sample in our study may involve an unusually high number of adolescents from less affluent and BAME backgrounds who are involved in social action, but this is unlikely to be representative of the UK as a whole. Further research akin to that conducted by Godfrey and Cherng (2016), on the effect of young people's local contexts on their civic participation, would provide greater insight into the difference that context makes to adolescents' ability to develop a habit of social action.

In terms of religiosity, those with a habit of social action are more likely than those who have not made a habit or not participated to be religious and practise their religion. Social action and charity are central to many religions, including Christianity and Islam, the UK's two biggest religions, and research in the UK and USA suggests a link between religion and social action participation (Pye and Michelmore 2017; Youniss et al. 1999). It may be worth considering how other institutions-particularly schools, colleges and universities - can play a supportive role for adolescents who are not religious, to help them to develop a habit.

Regression analysis showed that the defining feature of a habit of social action is perceived behavioural control, defined in our study as the young person's belief that it is possible for them to participate-that they have the time, skills, opportunity, and confidence to do so. This is particularly important for our study because social action is generally a behaviour 'over which people have incomplete volitional control' (Ajzen 1991: 181). As the Theory of Planned Behaviour suggests, intentions are important, but 'a behavioural intention can find expression in behaviour only ... if the person can decide at will to perform or not perform the behaviour' (Ajzen 1991: 181-182). Given that there is evidence to suggest that (perceived) lack of the aforementioned resources can be barriers to getting involved in social action, and their association with a habit of social action, it could also be argued that they may be barriers to making a habit of social action. It is known from wider research on inequality that it is hard for people who lack resources to take advantage of the opportunities available to the rest of society' (Darton et al. 2003: 9); social action can be considered one such opportunity. Therefore, improving access to resources, and removing the barriers that a lack of resources creates, should be key areas of focus for those looking to support adolescents to develop a habit of social action.

\section{Limitations}

There are several limitations to this study. The sampling strategy means that the respondents are not a probability sample, and those aged 18-20 are underrepresented compared to 16-17 year olds. However, although respondents cannot be said to represent all 16-20 year olds involved in social action in the UK, with over 4500 returns this still provides a useful sample. Furthermore, there are limitations to any self-report questionnaire-respondents may not respond accurately, there may be a social desirability response bias (Robson 2002: 233), and the issues with selfreported virtue identification include possible self-delusion or under-reporting (Arthur et al. 2015b: 13).

While no significant differences were found between the Habit, Non-habit and Non-participant groups in terms of FSM eligibility, it is not possible to say that socioeconomic status has no effect on a habit of social action. This is because FSM was the only measure used; additional questions also used as proxies for socioeconomic status, such as household income, occupation of chief income earner, and/or whether the respondent's parents went to university, would have elicited a more accurate picture of respondents' socioeconomic status.

In addition, it is not possible to ascertain levels of nonresponse bias for the questionnaire, since each organisation involved shared the questionnaire with adolescents in different ways: some sent it directly to a specific sample, while others advertised it on social media and school intranet sites. Nonetheless, the significant number of responses from adolescents who had not been involved with social action in the previous 12 months, as well as the demographic spread of the data, suggest that the questionnaire reached a broad range of respondents.

\section{Conclusion}

We can conclude that our hypothesis is correct: adolescents who have made a habit of social action (having participated in the previous 12 months and intending to participate again in future) are more likely than those without a habit (having participated in the past 12 months but not intending to, are unsure, or are only 'fairly likely' to participate again in future) and those who have not participated in the past 12 months to: participate more often in social action; intend to participate in social action in future; identify themselves more closely with moral and civic virtue exemplars, and say that other people who know them also think they are more like the moral and civic virtue exemplars; have parents and friends who are also involved in social action, and in particular, in the same kinds of 
activities as them; and believe they have the time, skills, opportunity and confidence to participate in social action.

We propose several policy, practice and research recommendations as a result of these findings. Importantly for youth social action providers, habit is malleable, making the education of habit possible (Kraftl 2015). Supporting adolescents to believe that they have the time, skills and confidence to participate in and make a habit of social action, and providing opportunities that are accessible, may help to reduce barriers to involvement in social action and barriers to making a habit of social action. This support can come from a variety of sources, such as home, peers, faith groups, and/or youth social action providers, or can be embedded into the character education offered by schools. Second, with parents' involvement in social action being related to their children's involvement, it is important that the opportunity to take part in and build a habit of social action is extended to adults as well as adolescents, enabling a culture of social action to become the norm. As such, initiatives aiming to increase participation in adult volunteering are likely to have a positive, knock-on effect on adolescents' participation too.

Third, further research is recommended. Experimental research could test whether increasing adolescents' perceived behavioural control over participating in social action improves their likelihood of taking part in the future. As part of this, an intervention which aims to increase this perceived behavioural control could be designed and tested. Longitudinal research, starting with a cohort of adolescents under the age of 10 and continuing until they are 20 , would enable an understanding of how adolescents develop a habit of social action over time, and the barriers and enablers to developing that habit. Finally, additional research to understand more about those identified as Nonparticipants-those who had not been involved in social action in the previous 12 months - would be valuable in helping to ascertain the barriers and enablers to their participation. Such studies would not only be valuable to the \#iwill campaign and similar initiatives, but would also help further academic knowledge on habit and social action.

Acknowledgements This study was conducted as part of the Jubilee Centre for Character and Virtues' 'Service Britain' programme, funded by the Templeton Foundation.

\section{Compliance with Ethical Standards}

Conflict of interest The authors declare that they have no conflict of interests.

Ethical Approval The study was approved by the Humanities and Social Sciences Ethical Review Committee at the University of Birmingham. Respondents in the pilot questionnaire were given time to read an information sheet and sign a consent form before participating. They could opt out of participating at any time up until the completed questionnaires had been collected. Adolescents opted into taking the online questionnaire, and information about the study was provided at the start of the questionnaire. Respondents also ticked a consent box to confirm that they understood the information and wanted to participate.

Open Access This article is distributed under the terms of the Creative Commons Attribution 4.0 International License (http://crea tivecommons.org/licenses/by/4.0/), which permits unrestricted use, distribution, and reproduction in any medium, provided you give appropriate credit to the original author(s) and the source, provide a link to the Creative Commons license, and indicate if changes were made.

\section{Appendix 1: Virtue Identity Measure}

\section{Moral Virtue Exemplar}

Ben cares about his friends. They feel like they can tell him anything and they can trust him not to judge them. When his friend Jamie told him that he was having problems at home, Ben didn't tell anyone else and tried to be there for him—he could understand how Jamie might be feeling.

\section{Performance Virtue Exemplar}

Saeed lives by the motto 'if at first you don't succeed, try again'. In a group he likes motivating others to reach their goals too. Even when things are difficult, Saeed bounces back-like last year, when he didn't get into the local football team. Ever since he's spent more time training and he'll try again this year.

\section{Intellectual Virtue Exemplar}

Daisy likes to make her views heard. She's open to hearing other people's points of view, too, which makes her a good listener. After two of her friends had a bad argument recently, Daisy was the one who sat down with them both, heard what they had to say, and got them to work things out.

\section{Civic Virtue Exemplar}

Emily is pretty active in her community. She generally knows about the important issues going on in the world and in her local area and helps out where she can when she has the time. When she found out that her youth club might be closed down, she and her friends started a campaign to keep it open.

\section{Questions About Each Exemplar}

- To what extent do you think you are like [exemplar]? 
- To what extent would you like to be a person like [exemplar]?

- To what extent would the people who know you say you are like [exemplar]?

- To what extent would your friends like someone like [exemplar]?

\section{Appendix 2: Demographic Data}

\begin{tabular}{lc}
\hline Demographic & $\%$ of sample (unweighted) \\
\hline Female & 67 \\
Male & 33 \\
16 & 40 \\
17 & 42 \\
18 & 12 \\
19 & 4 \\
20 & 2 \\
White & 70 \\
BAME & 30 \\
FSM & 24 \\
SEN & 8 \\
Disability & 11 \\
Religious & 43 \\
Practising religion & 42 \\
School & 10 \\
Sixth form & 44 \\
College & 41 \\
University & 4 \\
Working part-time & 15 \\
Working full-time & 1 \\
Apprenticeship & 1 \\
Internship & 1 \\
Unemployed & 10 \\
\hline
\end{tabular}

\section{Appendix 3: Binary Regression Model Test and Summary}

\begin{tabular}{llll}
\hline & Chi square & df & Sig. \\
\hline Omnibus tests of model coefficients & & \\
Step 1 & & & \\
Step & 320.810 & 12 & .000 \\
Block & 320.810 & 12 & .000 \\
Model & 320.810 & 12 & .000 \\
\hline
\end{tabular}

\begin{tabular}{llll}
\hline Step & $\begin{array}{l}-2 \text { Log } \\
\text { likelihood }\end{array}$ & $\begin{array}{l}\text { Cox \& Snell R } \\
\text { Square }\end{array}$ & $\begin{array}{l}\text { Nagelkerke R } \\
\text { Square }\end{array}$ \\
\hline \multicolumn{2}{l}{ Model summary } & & .308 \\
1 & $1345.663^{\mathrm{a}}$ & .227 & \\
\hline
\end{tabular}

${ }^{a}$ Estimation terminated at iteration number 5 because parameter estimates changed by less than .001

\section{References}

\#iwill (2017a). Making social action part of life for all young people by 2020 . http://www.iwill.org.uk/wp-content/uploads/downloadmanager-files/iwill_reviewdoc_digital_2017.pdf. Accessed.

\#iwill. (2017b). Youth social action. http://www.iwill.org.uk/down load-category/youth-social-action/. Accessed 28 April 2017.

Aarts, H., Paulussen, T., \& Schaalma, H. (1997). Physical exercise habit: On the conceptualization and formation of habitual health behaviours. Health Education Research: Theory and Practice, 12(3), 363-374. https://doi.org/10.1093/her/12.3.363.

Aarts, H., Verplanken, B., \& van Knippenberg, A. (1998). Predicting behavior from actions in the past: Repeated decision making or a matter of habit? Journal of Applied Social Psychology, 28, 1355-1374. https://doi.org/10.1111/j.1559-1816.1998.tb01681.x.

Ajzen, I. (1991). The theory of planned behavior. Organizational Behavior and Human Decision Processes, 50, 179-211. https:// doi.org/10.1016/0749-5978(91)90020-t.

Ajzen, I., \& Driver, B. L. (1991). Prediction of leisure participation from behavioral, normative, and control beliefs: An application of the theory of planned behavior. Leisure Sciences, 13(3), 185-204. https://doi.org/10.1080/01490409109513137.

Amato, P. (1990). Personality and social network involvement as predictors of helping behaviour in everyday life. Social Psychology Quarterly, 53, 31-43. https://doi.org/10.2307/ 2786867.

Andolina, M. W., Jenkins, K., Zukin, C., \& Keeter, S. (2003). Habits from home, lessons from school: Influences on youth civic engagement. Political Science and Politics, 36(2), 275-280. https://doi.org/10.1017/s104909650300221x.

Aristotle. (2000). Nicomachean ethics (trans: R. Crisp). Cambridge: Cambridge University Press.

Arthur, J., Harrison, T., \& Taylor, E. (2015a). Building character through youth social action. Jubilee Centre for Character and Virtues, University of Birmingham Report. Jubilee Centre for Character and Virtues, University of Birmingham, Birmingham. Available at https://www.jubileecentre.ac.uk/userfiles/jubileecen tre/pdf/Research\%20Reports/Building_Character_Through_ Youth_Social_Action.pdf. Accessed 18 July 2017.

Arthur, J., Harrison, T., Taylor-Collins, E., \& Moller, F. (2017). A habit of service: The factors that sustain service. Jubilee Centre for Character and Virtues, University of Birmingham Report. Jubilee Centre for Character and Virtues, University of Birmingham, Birmingham. Available at https://www.jubileecentre.ac. uk/userfiles/jubileecentre/pdf/Research\%20Reports/A_Habit_ of_Service.pdf. Accessed 1 Dec 2017.

Arthur, J., Kristjánsson, K., Walker, D., Sanderse, W., \& Jones, C. (2015b). Character education in UK schools: Research report. Jubilee Centre for Character and Virtues, University of Birmingham Report. Jubilee Centre for Character and Virtues, University of Birmingham, Birmingham. Available at https:// 
www.jubileecentre.ac.uk/1571/projects/previous-work/charac ter-education-in-uk-schools. Accessed 9 Jan 2016.

Astin, A. W., Sax, L. J., \& Avalos, J. (1998). Long-term effects of volunteerism during the undergraduate years. Review of Higher Education, 22, 187-202.

Australian Government. (2011). National volunteering strategy: Australia volunteers-inspiring the volunteer in you. Commonwealth of Australia, Department of the Prime Minister and Cabinet Report. Commonwealth of Australia, Department of the Prime Minister and Cabinet, Canberra. Available at https://www. volunteeringtas.org.au/wp-content/uploads/2015/11/other5.pdf. Accessed 17 Sept 2017

Ballard, P. J., Hoyt, L. T., \& Pachucki, M. C. (2018). Impacts of adolescent and young adult civic engagement on health and socioeconomic status in adulthood. Child Development. https:// doi.org/10.1111/cdev.12998.

Bandura, A. (1977). Social learning theory. Englewood Cliffs: Prentice-Hall. https://doi.org/10.1177/105960117700200317.

Berg, C., Jonsson, I., \& Conner, M. (2000). Understanding choice of milk and bread for breakfast among Swedish children aged 11-15 years: An application of the theory of planned behaviour. Appetite, 34(1), 5-19. https://doi.org/10.1006/appe.1999.0269.

Berkowitz, L., \& Lutterman, K. G. (1968). The traditional socially responsible personality. Public Opinion Quarterly, 32, 169-185. https://doi.org/10.1086/267597.

Birdwell, J., Scott, R., \& Reynolds, L. (2015). The double benefit of youth social action could help to tackle some of our most pressing social problems...: Service nation 2020. Demos Report. Demos, London. Available at https://www.demos.co.uk/files/ ServiceNation2020.pdf?1436715297. Accessed 15 Dec 2016.

Blasi, A. (2005). Moral character: A psychological approach. In D. K. Lapsley \& F. C. Power (Eds.), Character psychology and character education (pp. 67-100). Notre Dame, IN: University of Notre Dame Press.

Booth, C., Cameron, D., Cumming, L., Gilby, N., Hale, C., Hoolahan, F., et al. (2014). National Citizen Service 2013 Evaluation: Main report. National Citizen Service, Ipsos MORI Report. National Citizen Service, Ipsos MORI, London. Available at https://www. ipsos-mori.com/Assets/Docs/Publications/SRI-National-CitizenService-2013-evaluation-main-report-August2014.PDF. Accessed 9 Dec 2015.

Bown, H., Harflett, N., \& Gitsham, N. (2014). Embedding inclusive practices in opportunities for youth social action: A report of a study into 'what works' in enabling the full participation of all young people in social action. The National Development Team for Inclusion Report. The National Development Team for Inclusion, Bath. Available at http://www.ndti.org.uk/uploads/ files/iwill_NDTi.pdf. Accessed 7 Jan 2016.

Breeze, B., \& Thornton, A. (2006). Raising a giving nation: A report on 3 years of research and activity with young people and schools by the Giving Nation programme. Citizenship Foundation Report. Citizenship Foundation, London. Available at http:// www.citizenshipfoundation.org.uk/lib_res_pdf/0422.pdf. Accessed 10 July 2015.

Cabinet Office, \& Ipsos MORI. (2016). Youth Social Action Survey, 2015. UK Data Service. Accessed 25 Sept 2016.

Callero, P. L., Howard, J. A., \& Piliavin, J. A. (1987). Helping behavior as role behavior: Disclosing social structure and history in the analysis of prosocial action. Social Psychology Quarterly, 50, 247-256. https://doi.org/10.2307/2786825.

Clary, E. G., \& Miller, J. (1986). Socialization and situational influences on sustained altruism. Child Development, 57, 1358-1369. https://doi.org/10.2307/1130415.

Clary, E. G., Snyder, M., Ridge, R. D., Copeland, J., Stukas, A. A., Haugen, J., et al. (1998). Understanding and assessing the motivations of volunteers: A functional approach. Journal of
Personality and Social Psychology, 74(6), 1516-1530. https:// doi.org/10.1037//0022-3514.74.6.1516.

Darton, D., Hirsch, D., \& Strelitz, J. (2003). Tackling disadvantage: A 20-year enterprise. Joseph Rowntree Foundation Report. Joseph Rowntree Foundation, York. Available at http://www.sportni. net/sportni/wp-content/uploads/2013/03/Tackling_Disadvantage. pdf. Accessed 14 July 2017.

de Leeuw, A., Valois, P., Ajzen, I., \& Schmidt, P. (2015). Using the theory of planned behavior to identify key beliefs underlying pro-environmental behavior in high-school students: Implications for educational interventions. Journal of Environmental Psychology, 42, 128-138. https://doi.org/10.1016/j.jenvp.2015. 03.005 .

Erikson, E. (1968). Identity. Youth and crisis. New York, NY: Norton.

European Voluntary Service. (2016). European voluntary service: 20 Years. European Commission Report. European Commission, Available at https://europa.eu/youth/sites/default/files/evs_fact sheet_and_impacts_apr_2016.pdf. Accessed

Evans, K. (2011). 'Big Society' in the UK: A policy review. Children and Society, 25(2), 164-171. https://doi.org/10.1111/j.10990860.2010.00351.x.

Flanagan, C. A., Syvertsen, A. K., \& Stout, M. D. (2007). Civic measurement models: Tapping adolescents' civic engagement. CIRCLE Report. CIRCLE, Medord, MA. Available at http:// www.civicyouth.org/PopUps/WorkingPapers/WP55Flannagan. pdf. Accessed

Gaskin, K. (1998). Vanishing volunteers: Are young people losing interest in volunteering? Voluntary Action Journal, 1(1), 34-44. http://www.ivr.org.uk/images/stories/Institute-of-VolunteeringResearch/VA-Documents/VA1_1/article3_gaskin.pdf

Godfrey, E. B., \& Cherng, H.-Y. S. (2016). The kids are all right? Income inequality and civic engagement among Our Nation's Youth. Journal of Youth and Adolescence, 45, 2218-2232. https://doi.org/10.1007/s10964-016-0557-4.

Gollwitzer, P. M. (1999). Implementation intentions: Strong effects of simple plans. American Psychologist, 54(7), 493-503. https:// doi.org/10.1037//0003-066x.54.7.493.

Grönlund, H. (2011). Identity and volunteering intertwined: Reflections on the values of young adults. VOLUNTAS: International Journal of Voluntary and Nonprofit Organizations, 22(4), 852-874. https://doi.org/10.1007/s11266-011-9184-6.

Hall, T., Coffey, A., \& Williamson, H. (1999). Self, space and place: Youth identities and citizenship. British Journal of Sociology of Education, 20(4), 501-513. https://doi.org/10.1080/ 01425699995236.

Hardy, S. A., \& Carlo, G. (2011). Moral identity: What is it, how does it develop, and is it linked to moral action? Child Development Perspectives, 5(3), 212-218. https://doi.org/10.1111/j.17508606.2011.00189.x.

Hart, D., \& Fegley, S. (1995). Prosocial behavior and caring in adolescence: Relations to self-understanding and social judgment. Child Development, 66, 1347-1359. https://doi.org/10. 2307/1131651.

Hewitt, A., \& Stephens, C. (2007). Healthy eating among 10-13-yearold New Zealand children: Understanding choice using the theory of planned behaviour and the role of parental influence. Psychology, Health \& Medicine, 12(5), 525-535. https://doi.org/ 10.1080/13548500601164396.

Higgins, E. T. (1987). Self-discrepancy: A theory relating self and affect. Psychological Review, 94(3), 319-340. https://doi.org/10. 1037//0033-295x.94.3.319.

Ipsos MORI. (2014). Youth social action in the UK-2014: A face-toface survey of 10-20 year olds in the UK. Cabinet Office Report. Cabinet Office, Available at https://www.ipsos-mori.com/Assets/ Docs/Publications/sri-ecf-youth-social-action-in-the-uk-2014. pdf. Accessed 1 Dec 2014. 
Ipsos MORI. (2015). Youth Social Action in the UK-2015: A faceto-face survey of 10-20 year olds in the UK. London. Available at https://www.ipsos-mori.com/Assets/Docs/Publications/sriyouth-social-action-in-uk-2015.pdf. Accessed 1 Dec 2015.

Johnson, D. E. (1998). Applied multivariate methods for data analysts. Pacific Grove: Duxbury Press.

Jubilee Centre for Character and Virtues. (2014). Statement on character development and youth social action. Jubilee Centre for Character and Virtues, University of Birmingham Report. Jubilee Centre for Character and Virtues, University of Birmingham, Birmingham. Available at http://www.jubileecentre.ac. uk/userfiles/jubileecentre/pdf/StatementSocialAction.pdf. Accessed 27 Jan 2015.

Jubilee Centre for Character and Virtues. (2017). A framework for character education in schools. Jubilee Centre for Character and Virtues, University of Birmingham Report. Jubilee Centre for Character and Virtues, University of Birmingham, Birmingham. Available at https://www.jubileecentre.ac.uk/userfiles/jubileecen tre/pdf/character-education/Framework\%20for\%20Character\% 20Education.pdf. Accessed 16 June 2017.

Kirkman, E., Sanders, M., \& Emanuel, N. (2015). Evaluating social action, an interim report: Does participating in social action boost the skills young people need to succeed in adult life. Behavioural Insights Team Report. Behavioural Insights Team, London. Available at http://www.behaviouralinsights.co.uk/ sites/default/files/Evaluating\%20Youth\%20Social\%20Action An\%20Interim\%20Report_0.pdf. Accessed 18 May 2015.

Klimstra, T. A., Hale, W. W., III, Raaijmakers, Q. A. W., Branje, S. J., \& Meeus, W. H. J. (2010). Identity formation in adolescence: Change or stability? Journal of Youth and Adolescence, 39(2), 150-162. https://doi.org/10.1007/s10964-009-9401-4.

Kraftl, P. (2015). The force of habit: Channelling young bodies at alternative education spaces. Critical Studies in Education, 5, 1-15. https://doi.org/10.1080/17508487.2016.1102753.

Kremers, S. P., \& Brug, J. (2008). Habit strength of physical activity and sedentary behavior among children and adolescents. Pediatric Exercise Science, 20, 5-14. https://doi.org/10.1123/pes.20. 1.5 .

Lally, P., van Jaarsveld, C. H. M., Potts, H. W. W., \& Wardle, J. (2010). How are habits formed: Modelling habit formation in the real world. European Journal of Social Psychology, 40(6), 998-1009. https://doi.org/10.1002/ejsp.674.

Lamb, M., Taylor-Collins, E., \& Silverglate, C. (2019). Character education for social action: A conceptual analysis of the \#iwill campaign. Journal of Social Science Education.

Landis, D., Triandis, H. C., \& Adamopoulos, J. (1978). Habit and behavioral intentions as predictors of social behavior. The Journal of Social Psychology, 106(2), 227-237. https://doi.org/ 10.1080/00224545.1978.9924174.

Law, B. M. F., Shek, D. T. L., \& Ma, C. M. S. (2013). Validation of family, school, and peer influence on volunteerism scale among adolescents. Research on Social Work Practice, 23(4), 458-466. https://doi.org/10.1177/1049731513476144.

Lee, L., Piliavin, J. A., \& Call, V. R. A. (1999). Giving time, money, and blood: Similarities and differences. Social Psychology Quarterly, 62(3), 276-290. https://doi.org/10.2307/2695864.

Low, N., Butt, S., Ellis Paine, A., \& Davis Smith, J. (2007). Helping out: A national survey of volunteering and charitable giving. Cabinet Office Report. Cabinet Office, London. Available at http://www.ivr.org.uk/component/ivr/helping-out-a-national-sur vey-of-volunteering-and-charitable-giving. Accessed 3 May 2015.

Markus, H. R., \& Kitayama, S. (1991). Culture and the self: Implications for cognition, emotion, and motivation. Psychological Review, 98(2), 224-253. https://doi.org/10.1037//0033-295x. 98.2.224.
Marta, E., Manzi, C., Pozzi, M., \& Vignoles, V. L. (2014). Identity and the theory of planned behavior: Predicting maintenance of volunteering after three years. The Journal of Social Psychology, 154(3), 198-207. https://doi.org/10.1080/00224545.2014. 881769.

Marta, E., \& Pozzi, M. (2008). Young people and volunteerism: A model of sustained volunteerism during the transition to adulthood. Journal of Adult Development, 15, 35-46. https:// doi.org/10.1007/s10804-007-9033-4.

Mason, C., Cremin, H., Warwick, P., \& Harrison, T. (2010). Building voice, civic action and learning: Variation in levels of civic engagement amongst young people living in areas of socioeconomic disadvantage. EngagEd Report. EngagEd, Cambridge. Available at http://engaged.educ.cam.ac.uk/publications/Semi nar\%202\%20Listening\%20harder\%20paper\%20HC.pdf. Accessed 24 July 2015.

Meer, J. (2013). The habit of giving. Economic Inquiry, 51(4), 2002-2017. https://doi.org/10.1111/ecin.12010.

Metz, E. (2014). State of the field: Youth community service in the USA. In A. Ben-Arieh, F. Casas, I. Frønes, \& J. E. Korbin (Eds.), Handbook of child well-being: Theories, methods and policies in global perspective (pp. 977-997). Netherlands: Springer. https:// doi.org/10.1007/978-90-481-9063-8_34.

Metz, E., \& Youniss, J. (2003). A demonstration that school-based required service does not deter-but heightens-volunteerism. Political Science and Politics, 36, 281-286. https://doi.org/10. 1017/s1049096503002221.

Mittal, B. (1988). Achieving higher seat belt usage: The role of habit in bridging the attitude-behavior gap. Journal of Applied Social Psychology, 18, 993-1016. https://doi.org/10.1111/j.1559-1816. 1988.tb01189.x.

Moshman, D. (2011). Adolescent rationality and development: Cognition, morality and identity. New York, NY: Psychological Press. https://doi.org/10.4324/9780203835111.

National Youth Agency. (2013). Young people and positive social action: Exploring the relationship between instrumental and altruistic motivation-an evaluation of the National Youth Agency Social Action Fund programme (Round 2). National Youth Agency Report. National Youth Agency, Leicester. Available at http://www.stchads.ac.uk/wp-content/uploads/ 2015/09/Young-People-and-Postive-Social-Action-NYA-SocialAction-Fund-evaluation-report-2013.pdf. Accessed 30 March 2015.

Omoto, A. M., \& Snyder, M. (1995). Sustained helping without obligation: Motivation, longevity of service, and perceived attitude change among AIDS volunteers. Journal of Personality and Social Psychology, 68(4), 671-686. https://doi.org/10.1037// 0022-3514.68.4.671.

Ouellette, J. A., \& Wood, W. (1998). Habit and intention in everyday life: The multiple processes by which past behavior predicts future behavior. Psychological Bulletin, 124, 54-74. https://doi. org/10.1037/0033-2909.124.1.54.

Pancer, S. M., \& Pratt, M. W. (1999). Social and family determinants of community service involvement in Canadian youth. In J. Youniss \& M. Yates (Eds.), Roots of civic identiy: International perspectives on community service and activism in youth (pp. 32-55). Cambridge: Cambridge University Press. https://doi.org/ 10.1017/cbo9780511751820.004.

Penner, L. A. (2002). Dispositional and organizational influences on sustained volunteerism: an interactionist perspective. Journal of Social Issues, 58(3), 447-467. https://doi.org/10.1111/15404560.00270.

Pye, J., \& Michelmore, O. (2017). National youth social action survey 2016. \#iwill campaign, Ipsos MORI Report. \#iwill campaign, Ipsos MORI, London. Available at https://www.ipsos.com/ipsos- 
mori/en-uk/national-youth-social-action-survey-2016. Accessed 4 Jan 2018.

Rest, J. (1983). Morality. In P. H. Mussen, J. Flavell, \& E. Markman (Eds.), Handbook of child psychology: Cognitive development (pp. 556-629). New York, NY: Wiley.

Robson, C. (2002). Real world research. Oxford: Blackwell Publishing.

Rosen, H. S., \& Sims, S. T. (2011). Altruistic behavior and habit formation. Nonprofit Management and Leadership, 21(3), 235-253. https://doi.org/10.1002/nml.20023.

Sarre, S., \& Tarling, R. (2010). The volunteering activities of children aged 8-15. Voluntary Sector Review, 1(3), 293-307. https://doi. org/10.1332/204080510X538301.

Steutel, J., \& Spiecker, B. (2004). Cultivating sentimental dispositions through aristotelian habituation. Journal of Philosophy of Education, 38(4), 531-549. https://doi.org/10.1111/j.03098249.2004.00403.x

United Nations.(2001). 'Marking end of international year of volunteers, General Assembly encourages all people to become more engaged in voluntary activities' General Assembly. Available at: https://www.un.org/press/en/2001/GA9990.doc. htm. Accessed 24 Nov 2017.

United Nations. (2015). Resolution adopted by the General Assembly on 25 September 2015: Transforming our world: the 2030
Agenda for Sustainable Development. United Nations Report. United Nations, New York. Available at http://www.un.org/ga/ search/view_doc.asp?symbol=A/RES/70/1\&Lang=E. Accessed 8 Aug 2018.

van Ryn, M., \& Vinokur, A. D. (1992). How did it work? An examination of the mechanisms through which an intervention for the unemployed promoted job-search behavior. American Journal of Community Psychology, 20(5), 577-597. https://doi. org/10.1007/bf00941773.

Verplanken, B. (2006). Beyond frequency: Habit as mental construct. British Journal of Social Psychology, 45, 639-656. https://doi. org/10.1348/014466605x49122.

Verplanken, B., Aarts, H., van Knippenberg, A., \& van Knippenberg, C. (1994). Attitude versus general habit: Antecedents of travel mode choice. Journal of Applied Social Psychology, 24, 285-300. https://doi.org/10.1111/j.1559-1816.1994.tb00583.x.

Verplanken, B., \& Orbell, S. (2003). Reflections on past behaviour: A self-report index of habit strength. Journal of Applied Social Psychology, 33(6), 1313-1330. https://doi.org/10.1111/j.15591816.2003.tb01951.x.

Youniss, J., McLellan, J. A., \& Yates, M. (1999). Religion, community service, and identity in American youth. Journal of Adolescence, 22(2), 243-253. https://doi.org/10.1006/jado.1999. 0214. 